\title{
A LINGUAGEM DAS MERCADORIAS
}

\section{The language of goods}

Lucia Santaella ${ }^{1}$

Winfried Nöth ${ }^{2}$

\section{Resumo}

Mercadorias têm sido estudadas pela economia, economia política e, evidentemente, pelo marketing. Tendo como base a semiótica, ciência geral de todos os tipos de signos e seus respectivos modos de produzir sentido, este artigo visa analisar as mercadorias em sua natureza e funcionamento de linguagem. Para isso, depois de examinar as teorias semióticas das mercadorias e as abordagens antropológicas, as mercadorias são apresentadas como signos em uma visão pluralista. Assim, a mercadoria é contemplada como signo utilitário, como signo comercial e como signo sociocultural. Por fim, são analisados os processos de semiotização por que passam as mercadorias e a linguagem da mercadoria como um sistema.

Palavras-chave: mercadoria, signos, linguagem, sistema.

\begin{abstract}
Commodities have been studied by economy, political economy, and, certainly, marketing. Based on semiotics, the general science of all types of signs and their respective modes of producing sense, this paper aims at analysing commodities in their nature and functioning as language. After examining the semiotic theories of commodities and the anthropological approaches, commodities are presented as signs in a pluralistic view. Hence, commodities are seen as utilitarian signs, as commercial signs and as social-cultural signs. In the end, the processes of commodities semiotization and the language of commodities as a system are analysed.
\end{abstract}

Key words: commodities, signs, language, system.

\section{Resumen}

Las mercancías han sido estudiadas por ciencias como la economía, economía política e evidentemente por el marketing. Tomando como base la semiótica, ciencia que estudia todos los tipos de signos y sus respectivos modos de producir sentido, este trabajo

\footnotetext{
${ }^{1}$ Professora Titular da PUC-SP junto ao Progarma de Pós-Graduação em Comunicação e Semiótica.

${ }^{2}$ Professor Titular da Universidade de Kessel na Alemanha.
} 
reflexiona sobre las mercancías en su naturaleza y conformación del lenguaje. Para esto, después de examinar las teorías semióticas sobre las mercancías y su abordaje antropológico, las mercancías son presentadas como signo en sus diversos sentidos. Como tal, la mercancía es vista como un signo utilitario, un signo comercial y como un signo sociocultural. Finalmente, son analizados los procesos de semiotización por los que pasan las mercancías y el lenguaje de las mercancías como un sistema.

Palabras-clave: mencancías, signos, lenguaje, sistema.

\section{SEMIÓTICA DAS MERCADORIAS: ESTADO DA ARTE}

O caráter sígnico das mercadorias tem sido analisado em estudos semióticos explícitos e em um bom número de trabalhos de semiótica implícita, desenvolvidos no campo da pesquisa de marketing, economia política e antropologia.

\subsection{Semiótica das mercadorias na pesquisa de marketing}

Na pesquisa de marketing, os aspectos semióticos das mercadorias vêm sendo estudados primariamente dentro de três campos complementares de pesquisa: publicidade, pesquisa de imagem de marca e teoria do consumo simbólico. Uma revisão da pesquisa nessa área não cabe no presente contexto, mas suas implicações semióticas devem ser comentadas mesmo que de modo breve.

\subsubsection{Publicidade}

De um ponto de vista semiótico, a pesquisa em publicidade estuda as mensagens que são criadas sobre as mercadorias. Tais mensagens são o discurso de um produtor, de um anunciante que se dirige a consumidores potenciais.

As mensagens consistem de signos verbais e não-verbais, impressos, áudio e audiovisuais, e o produto anunciado é o objeto referido por esses signos. Pesquisas da imagem de marca e do consumo simbólico, por seu lado, estudam as estratégias comunicativas das mercadorias como mensagens.

\subsubsection{Pesquisa de imagem de marca}

Dessa perspectiva, as mercadorias são estudadas como signos cujo significado está 
na "imagem de marca" escolhida pelo consumidor diante de um elenco de ofertas (ver Perez 2004). Os componentes semânticos de uma imagem de marca, de acordo com Levy (1978: 168), incluem questões técnicas, características do produto, valor financeiro e adequação social. Semioticamente, tais componentes constituem o significado (ou conteúdo) do produto, enquanto o objeto material é o significante da mercadoria como um signo.

\subsubsection{Pesquisa sobre consumo simbólico}

O consumo simbólico (cf. Hirschman e Holbrooks 1981a), já descoberto por Veblen (1899), na forma de consumo conspícuo, é um ato de comunicação, não entre anunciante e consumidor, mas entre este e quaisquer outros membros da sociedade, possivelmente entre o consumidor e seu próprio ego. O signo, no consumo simbólico, é menos a mercadoria, ela mesma, do que o ato de consumir. Como foi sumarizado por Belk et al. (1982: 6), a teoria do consumo simbólico tem o seguinte pressuposto a respeito de tal signo: quer o consumo comunique claramente o status do consumidor ou não, fica claro que há ainda um número de inferências sobre as pessoas que são afetadas por essas mercadorias e serviços que elas presumivelmente selecionaram. Se as inferências são extraídas das mercadorias (por exemplo, carros) em relação aos seus usuários (por exemplo, seu tipo de personalidade), as mercadorias são interpretadas como signos indexicais. O significado desse índice não é um traço característico do objeto comercial ele mesmo (quer dizer, sua utilidade ou beleza de estilo). Tomada como um índice, a mercadoria refere-se a um atributo que supostamente caracteriza seu consumidor. Uma linguagem das mercadorias, baseada em tais signos indiciais, é uma linguagem sobre os usuários das mercadorias.

\subsection{Teorias semióticas das mercadorias}

Uma vez que todo o universo está permeado de signos (Peirce 1906: CP 5.448n.) e a semiótica é a ciência que estuda a vida dos signos na sociedade (Saussure 1916: 16), essa ciência, assim caracterizada por seus fundadores, parece estar predestinada ao estudo dos signos no mercado. Mas não faz muito tempo que a pesquisa nesse campo descobriu os métodos da semiótica (cf. Mick 1986; Umiker-Sebeok 1987), muito embora alguns semioticistas tenham trabalhado nessa área já nos anos 1960, exemplarmente Barthes (1964b).

A pesquisa de semiótica explícita mais extensiva sobre mercadorias tem sido 
realizada no contexto da semiótica da publicidade, que é o estudo das mensagens sobre mercadorias. $\mathrm{O}$ estudo das mercadorias elas mesmas como mensagens tem permanecido menos explorado. Este seria um ramo de uma teoria mais geral dos objetos (Krampen 1979: 6-21). Um tópico central nesse campo de pesquisa tem se voltado para a busca de um limiar semiótico entre a esfera de objetos não-semióticos e objetos com função sígnica, como quer Eco (1976: 19-28). Duas propostas para tal limiar, um alto e um baixo, serão discutidas abaixo.

\subsubsection{Publicidade e mitos da mercadoria}

Embora não esteja nos objetivos deste artigo apresentar a semiótica da publicidade, esta é muito relevante para a questão em discussão. O discurso público sobre a mercadoria gera significados que transformam o objeto comercial em signo. Tendo o consumidor absorvido esses significados, ele provavelmente, em certo nível de sua consciência, redescobrirá esse signo no mercado, dentro do sistema de mercadorias. Entre esses significados textualmente gerados, os semioticistas têm prestado atenção especial às conotações, significados secundários, subsentidos que são interpretados como estando, por assim dizer, incrustados, de modo parasitário, nos significados primários da mercadoria. Seguindo Barthes (1964a, b), sistemas com tais significados foram interpretados como mitos (Langholz-Leymore 1975) ou ideologias (Williamson 1978), conforme também será discutido mais abaixo.

\subsubsection{Semiotização sociocultural}

Uma das primeiras interpretações semióticas das mercadorias como signos foi proposta por Barthes (1964a: 41-2). Para ele, o limiar entre o semiótico e o não semiótico parece estar no aspecto utilitário ou funcional dos objetos (embora ele chame esses aspectos de funções sígnicas (ibid.: 41, 68)). Barthes reconheceu que as mercadorias e outros objetos da cultura "têm uma substância de expressão cuja essência não é significar", por exemplo, "roupas são usadas para a proteção e comida para alimentar, mesmo se elas forem também usadas como signos”. Mas, em um inevitável processo de semantização, esses objetos utilitários ficam "permeados de significados". "Tão logo exista uma sociedade, todo uso é convertido em um signo de si mesmo".

Barthes (ibid.: 41) discutiu dois aspectos dessa semantização. O primeiro pode ser chamado de signo sociocultural. Seu exemplo: “o uso de uma capa de chuva não pode ser 
dissociado dos próprios signos de uma situação atmosférica". O segundo pode ser chamado de signo econômico. Sua moldura de referência é o sistema de mercadorias:

\footnotetext{
"Uma vez que nossa sociedade produz apenas objetos padronizados, normalizados, esses objetos inevitavelmente são atualizações de um modelo, as substâncias de uma forma significante. Para descobrir um objeto não significativo, deve-se imaginar um utensílio absolutamente improvisado que não apresenta qualquer similaridade com um modelo existente" (ibid.: 41-2).
}

O limiar semiótico, que Barthes caracteriza entre os aspectos utilitário e sociocultural dos objetos, foi visto da mesma maneira por vários outros semioticistas, em especial na semiótica funcional de Mukařovský (1978: 40), desenvolvida entre 1930-40, que estabelece uma linha divisória muito clara entre as esferas do prático, no qual a manipulação dos objetos ocorre, e a esfera semiótica que implica uma consideração mediada dos objetos.

\subsubsection{Semiotização do utilitário}

Muito raramente, a esfera semiótica tem sido estendida para o campo da utilidade funcional, mas Moles (1972) propõe tal extensão na sua teoria dos objetos. O autor (1972: 48) define o significado de um objeto como sendo "largamente ligado à sua função, sua utilidade em relação ao repertório das necessidades humanas”. Para ele, a função prática de uma mercadoria encontra-se no seu significado denotativo. No seu estudo de tal significado, Moles combina princípios da semântica estrutural com métodos de psicosemântica. O significado de um objeto assim descoberto é similar ao significado lexicográfico da palavra, pela qual o objeto é designado. Por exemplo, o significado do objeto "faca", de acordo com essa teoria, poderia ser "corte agudo com um pegador, usado como um instrumento cortante". Em adição a essa camada primária de significado, Moles também estuda camadas secundárias de significado que são definidas como "estéticas ou conotativas".

\subsection{A semiótica da economia política}

Outras abordagens semióticas dos bens de consumo foram desenvolvidas na moldura da economia política na qual a essência semiótica da mercadoria foi primeiramente buscada no seu valor de uso e seu valor de troca. Karl Marx já havia usado a metáfora da "linguagem das mercadorias (na qual o tecido produz seus pensamentos)", isto 
é, traz uma mensagem (Capital I, 2.2).

Os principais representantes de uma semiótica da economia política são Lefebvre (1966: 342), Rossi-Landi (1975: 128) e Baudrillard (1968, 1972). Cumpre acrescentar aqui que, para este último (1968: 276-7), as mercadorias se tornam signos dentro do processo de consumo, que é por ele considerado como "uma atividade sistemática de manipulação sígnica". Sob esse ponto de vista, o objeto material e funcional adquire significado em um "sistema abstrato de relações com todos os outros objetos, nunca em sua materialidade, mas na sua diferença" em relação a todas as outras mercadorias. Como na língua, na qual a substância material (fonética e escrita) das palavras é essencialmente irrelevante (arbitrária) para o seu conteúdo, as mercadorias são signos cuja substância material é igualmente arbitrária: "Evidentemente, não são nunca os objetos que são consumidos, mas a idéia da relação que é consumida na série de objetos que originaram a idéia". Com essa visão radical da semiótica do consumo, a semantização dos objetos atingiu um clímax insuperável de modo que não parece mais haver traço material de funcionalidade prática nos objetos.

\subsection{Abordagens antropológicas}

A extrema insistência de Baudrillard na essência semiótica das mercadorias em detrimento de sua função utilitária encontra paralelo na proposta de alguns antropólogos, tais como Sahlins (1976) e Douglas e Isherwood (1979).

Marshall Sahlins tenta determinar o status dos bens, de um lado, na cultura, de outro, nas razões práticas. Enquanto a lógica da razão prática interpreta os bens como tendo valores de uso naturais, a lógica da cultura descreve os bens como signos arbitrários dentro de um sistema sociocultural de valores. Sahlins (ibid.: 169) opta pela segunda alternativa e conclui: "O significado social de um objeto, que o torna útil para certa categoria de pessoas, não é mais aparente em suas propriedades físicas, mas depende do valor que lhe pode ser acrescido na troca. O valor de uso não é menos simbólico ou menos arbitrário do que o valor da mercadoria".

Essa tese do caráter semiótico dos bens e mercadorias nunca foi mais radicalmente defendida do que por Mary Douglas e Baron Isherwood (1979). Na sua antropologia dos bens, eles vão tão longe a ponto de rejeitar por completo (como Baudrillard) a idéia do valor de uso:

"A função essencial do consumo está na sua capacidade de fazer sentido. Esqueçamos a idéia de irracionalidade do consumo. Esqueçamos a idéia de que as mercadorias são boas 
para comer, vestir, proteger, esqueçamos sua utilidade e tentemos, em lugar disso, pensar na idéia de que as mercadorias são boas para pensar, tratá-las como um meio para a faculdade criativa humana" (ibid: 62).

Outros antropólogos defensores da dimensão não-utilitária dos objetos de troca cultural são Csikszentmihalyi e Rochberg-Halton (1981), no seu estudo da significância psicológica e cultural do apego que os norte-americanos têm aos objetos em seus lares. Wallendorf e Arnould (1988) apresentam uma perspectiva cultural comparativa dos comportamentos em relação a "coisas favoritas". Outra pesquisa antropológica sobre a evolução dos valores culturais associados com as mercadorias foi realizada por Appadurai (1986).

A partir dos anos 1980 e, mais acentuadamente, dos anos 1990, com a crescente complexidade do mundo globalizado, com a expansão dos mercados e emergência de novos hábitos de consumo, a pesquisa etnográfica, tradicionalmente uma modalidade da antropologia aplicada, passou a ser utilizada como uma ferramenta do marketing.

A etnografia é um método antropológico em que os pesquisadores convivem comum grupo humano tendo em vista compreender - por meio da observação atenta, participativa, mas não interferente - seus hábitos, costumes, crenças, rituais, enfim, seu modo de vida. Quando transposto para o mercado, o pesquisador se insere no ambiente do consumidor, buscando observar e identificar o comportamento de uso que este último exibe na sua vida cotidiana.

Embora não substitua os métodos mais convencionais de pesquisa de mercado, a pesquisa etnográfica, como uma modalidade específica de pesquisa qualitativa, tem se consagrado no contexto do consumo. Uma vez que, depois de registradas pelos pesquisadores, as observações têm de ser devidamente interpretadas, nesta fase da pesquisa, o método etnográfico faz fronteira com a semiótica, na medida em que esta se caracteriza, sobretudo, como método de interpretação dos processos de significação dos signos.

\section{MERCADORIAS COMO SIGNOS EM UMA VISÃO PLURALISTA}

Para superar visões parciais dos processos de semiotização das mercadorias, é preciso lembrar que a utilidade prática também é uma dimensão relevante, sem a qual mercadorias não poderiam ser também signos. Pesquisas de imagem de marca mostraram que os consumidores certamente associam significados utilitários ou práticos com as mercadorias. Esses significados são constituintes das mercadorias como signos, significados que são apreendidos pelos consumidores tanto por meio das publicidades 
quanto por meio de sua experiência prática em atos individuais de compra. A essência semiótica dos bens de consumo não pode, portanto, ser esgotada por dicotomias tais como "utilitário vs. semiótico" ou "signo vs. não-signo". Assim também a dicotomia entre denotação e conotação não é uma ferramenta suficiente para a descrição da pluralidade de significados associados com as mercadorias.

\subsection{O signo multi-molduras: pressupostos básicos}

Em lugar de visões dicotômicas, uma abordagem pluralística da semiótica dos bens de consumo será proposta a seguir. O pressuposto básico é o de que as mercadorias são objetos que são percebidos pelos consumidores de várias perceptivas (cf. Eco 1976: 24-7) ou, na terminologia das ciências cognitivas, a partir de várias molduras.

\subsubsection{Molduras semióticas das mercadorias}

Há três molduras semióticas prototípicas: a utilitária, a comercial e a sociocultural, esta última em um sentido estreito. As esferas de significado associadas com essas molduras não são desconhecidas do consumidor e da pesquisa de marketing, mas os semioticistas tendem a negligenciar as molduras utilitárias e comerciais.

O número de possíveis molduras que determinam a percepção das mercadorias não se limita necessariamente a três. Uma das molduras adicionais que poderia ser estabelecida por uma diferenciação mais detalhada seria a psicológica. De um ponto de vista filosófico, tem havido propostas para o estabelecimento de molduras universais de visão de mundo, desde os três mundos de Popper e Eccles (1977) até os sete níveis de semiogênese de Kochs (1986: 167).

\subsubsection{A mercadoria como um signo multi-molduras}

Dentro de cada moldura, a mercadoria é vista como um signo que, dentro da tradição saussuriana, consiste de um significante e um significado. O significante é a substância significativa e forma da mercadoria, o veículo ou meio pelo qual a mensagem é transmitida. O significado é o conteúdo específico de cada signo. Em outras palavras, argumenta-se que a mercadoria como signo multi-molduras está tipicamente associado a três campos semânticos. 


\subsubsection{Signos atuais e potenciais}

Toda mercadoria é apenas um signo potencial e cada uma de suas quatro perspectivas são dimensões semióticas apenas virtuais. Em situações de compra ou uso, a mercadoria pode aparecer dentro de molduras não-semióticas. A mercadoria não é sempre um signo, nem é apenas um não-signo per se. É apenas em um contexto pragmático dado que o signo potencial se torna um signo atual. Entretanto, no marketing e na publicidade, o foco se volta tipicamente para o caráter sígnico da mercadoria.

\subsubsection{Fontes dos significados das mercadorias}

Há três fontes principais dos significados das mercadorias:

(a) o discurso do anunciante (descrições e anúncios) sobre o produto e a interpretação desse discurso pelo consumidor, que pode aceitar, rejeitar ou ignorar os significados propostos; (b) as preferências pessoais do consumidor ou experiências com o produto em seus atos prévios de consumo;

(c) o conhecimento que o consumidor tem do sistema de mercadorias que consiste do seu conhecimento dos produtos concorrentes no mercado.

Os significados gerados pelo anunciante e pelo consumidor refletem dois interesses antagônicos e perspectivas da mercadoria. Enquanto os significados do anunciante são tipicamente eufóricos com respeito ao produto, nunca focalizando em quaisquer de seus possíveis traços negativos, o consumidor idealmente crítico vê com ceticismo os argumentos auto-interessados do anunciante.

\subsection{O signo utilitário e o limiar semiótico}

Para aqueles que advogam uma separação nítida entre o prático e o semiótico ou mesmo definem o semiótico como não utilitário, a simples expressão "signo utilitário" soa como uma contradição de termos.

\subsubsection{O limiar semiótico e não semiótico}

Em oposição àqueles que assumem a existência de um limiar semiótico entre as esferas do utilitário e do semiótico, assumimos que os objetos utilitários podem ser vistos 
como semióticos ou não-semióticos. A diferença não é a de um limiar entre duas classes de objetos ou eventos, mas é aquela da perspectiva do usuário ou percipiente: em uma perspectiva utilitária, a mercadoria é usada (por exemplo, uma bicicleta ou um carro) ou é consumida (por exemplo, uma lata de cerveja). Uso e consumo envolvem uma manipulação imediata ou transformação do objeto (cf. Mukařovský 1978), porém as características de uso e consumo também podem ser referidas como um ato de semiose, isto é, de ação sígnica que é a ação de produzir uma interpretação.

\subsubsection{O signo utilitário}

No nível utilitário da semiose, há duas perspectivas da mercadoria como signo. Na perspectiva do consumidor, a mercadoria como signo utilitário está associada com aspectos relacionados ao seu valor de uso prático. Em adição, a perspectiva do produtor inclui a quantidade de trabalho ou o material requerido para a sua produção. Entretanto, iremos nos concentrar aqui na perspectiva do consumidor. Para este, a mercadoria como signo apresenta como traços a confiabilidade técnica, durabilidade, uso prático, adequação, ajustamento ao gosto. Uma máquina de lavar, por exemplo, cuja marca inclui traços como "alta qualidade", "confiabilidade" ou "economia", torna-se um signo desses conceitos utilitários mesmo que o usuário nunca tenha utilizado uma máquina dessa marca. Um exemplo típico desse funcionamento sígnico encontra-se na campanha, lançada pela Brastemp no Brasil, há alguns anos. O consumidor poderia não ter o produto da marca Brastemp, mas a publicidade visava transformar o signo da Brastemp em seu ponto de referência máxima.

Outros exemplos de significados utilitários são o gosto e os valores nutricionais dos produtos de alimentação, as qualidades de proteção ao corpo das vestimentas (cf. Holman, 1981a), as instruções para o cuidado dos tecidos etc. Esses traços semióticos não necessariamente têm de coincidir com quaisquer características reais ou qualidades verdadeiras do produto, tal como eles se revelariam em testes científicos. Por isso mesmo, para dar credibilidade ao produto, muitas campanhas publicitárias, por exemplo, na categoria higiene e laundry, colocam ênfase nos laboratórios de pesquisa que deram origem ao produto.

\subsubsection{Fatos e signos utilitários}

As características referenciais do signo utilitário não são idênticas aos "fatos 
utilitários", isto é, as características e funções do produto no seu uso prático. Não estamos negando o estatuto não-semiótico desses "fatos reais" físicos, técnicos, bioquímicos ou outros. Com o devido ceticismo sobre a possibilidade de se atingir objetividade científica, pode-se afirmar que as características do produto reveladas nos testes com os consumidores chegam muito perto da representação das características utilitárias não-semióticas de uma mercadoria. Apenas um consumidor crítico ideal, que estuda e aprende sobre essas características, pode desenvolver um signo utilitário da mercadoria cujas características correspondem muito proximamente desses "fatos" não semióticos, embora não seja uma questão semiótica se a máquina de lavar é realmente durável e confiável no seu uso cotidiano, ou não. Uma questão realmente semiótica é se os consumidores estão convencidos da durabilidade da marca específica de uma máquina de lavar.

No nível da semiose, deve ser considerado que tais convicções podem ser baseadas em pressupostos falsos. Como foi apontado por Eco (1976: 7) "um signo é tudo aquilo que pode ser tomado como significativamente capaz de substituir uma outra coisa. Esta outra coisa, não precisa necessariamente existir ou estar efetivamente em um determinado lugar no momento em que o signo se refere a ela. Assim, a semiótica é, em princípio, também uma disciplina que estuda tudo aquilo que pode ser utilizado para se mentir.

\subsection{O signo comercial}

Como um signo comercial, uma mercadoria significa seu valor de troca, seu valor comercial em relação a outros produtos no sistema de mercadorias. $\mathrm{O}$ indicador mais direto desse valor é o preço, mas ele também inclui outros fatores que aumentam ou diminuem os custos do produtor e do consumidor, tais como escassez, liquidações e garantias de serviços. Alguns produtos apresentam um valor de troca que é inerente à imagem de marca do consumidor, por exemplo, uma Ferrari conota luxo, enquanto o carro Lada era conhecido como o produto mais barato dentro da categoria. Outros significados comerciais são gerados pelas estratégias de preços do vendedor (por exemplo, a promessa de uma boa barganha ou a concessão na desculpa de que boa qualidade tem seu preço). Muitas campanhas publicitárias para produtos de massa omitem a perspectiva comercial e criam a imagem de um produto sem preço. Nesses casos, a mercadoria se torna um signo comercial potencial, atualizando-se apenas nas lojas ou supermercados que constroem seus próprios sistemas variáveis de mercadorias como signos comerciais.

\subsection{O signo sociocultural}


$\mathrm{O}$ anunciante que apresenta e o consumidor que percebe uma mercadoria como um signo sociocultural correlacionam o produto com o grupo social ou cultura que, sob seus pontos de vista, estão tipicamente associados com ele. Deve ser enfatizado que o termo cultura, neste contexto, é usado em um sentido estreito. Em um sentido mais vasto, cultura, certamente, inclui tanto a esferas do comércio quanto da utilidade prática (por exemplo, tecnologia).

A moldura sociocultural engloba um grande número de sub-molduras ou possivelmente super-molduras cujas inter-relações precisas não desenvolveremos neste trabalho, mas duas dentre essas molduras socioculturais serão brevemente discutidas abaixo. Outras sub-molduras socioculturais importantes para a semiotização das mercadorias são, por exemplo, a moldura estética e a moldura do sagrado (cf. Kopytoff 1986: 73-76). Dentro dessas duas molduras, o estatuto de mercadoria do produto fica obliterado até o ponto de transformá-lo em um objeto não-comercial.

\subsubsection{A sub-moldura sociológica}

Os produtos podem ser consumidos para indicar a afiliação do consumidor a certo grupo sociológico (cf. Holman, 1981b). Mesmo que o consumidor não pretenda que tal signo sociológico indicador apareça, um observador muitas vezes decodificará tais atos de consumo dessa maneira. Nestes casos, o produto funciona como um signo sociológico.

O grupo social ao qual a mercadoria está relacionada pode ser pequeno (adolescentes de certo estrato social) ou pode ser referir a toda uma cultura ("the American way of life"). Mais do que quaisquer outros aspectos das mercadorias como signos, os signos sociológicos estão submetidos a mudanças históricas. Tais mudanças podem ser rápidas, como ocorre com produtos ligados à moda ou estilos, ou podem ser mais lentas, como é o caso de produtos relacionados com estereótipos nacionais.

O ritmo de transformação das sociedades no capitalismo tardio tem se acelerado cada vez mais, trazendo mudanças profundas na antiga estabilidade dos grupos sociais. Nas palavras de Carreira (2007: 105):

"A sociedade industrial massificada da modernidade colocava o indivíduo como participante de grupos contratuais, com função específica: trabalhador, pai, sócio de clube etc. Todos com seus estilos de vida definidos e perenes com uma identidade clara. A sociedade complexa pós-moderna deslocou essa lógica do indivíduo, com uma identidade, para pessoas que assumem um papel efêmero, como participantes das tribos urbanas. " 
Citando Di Nallo (1999), o autor identifica as tribos do consumo como partes dos pontos de encontro, "ou bolhas que se formam na superfície de estruturas que se distinguem umas das outras por meio de vários critérios, mas sem apresentar um denominador comum entre elas que possibilite uma segmentação. Essas estruturas representam a complexidade da sociedade de consumo atual".

De qualquer maneira, há ainda mercadorias detectáveis como signos sociológicos, como é o caso de carros, alimentação e produtos de moda. Exemplos disso podem ser encontrados na pizza e no hamburger, como se referindo aos modos de vida italianos e americanos. O BMW e o Renault como se referindo aos estilos de padrões tecnológicos alemães e franceses. Mais evidente é o valor do signo sociológico das vestimentas (cf. Barthes 1967; e Holman 1981a). Suas dimensões sociais se estendem das profissões (o chapéu do homem de negócios londrino) ao folclore regional (a roupa bávara) e da cultura de massas (a cultura do blue jeans).

Como já foi afirmado, nenhum produto é, por definição, consumido como um signo. Alguns produtos parecem mesmo totalmente restritos a uma perspectiva utilitária não semiótica. Ferramentas, tais como martelo, pregos, parafusos são típicos dessa categoria de mercadoria. Entretanto, mesmo esses produtos podem ser tornar signos socioculturais. Pregos e martelos têm um potencial natural de serem associados a marceneiros e não a aristocratas ou acadêmicos. Outros exemplos de semiotização sociológica podem ser encontrados na lexicologia. Assim, a língua alemã distingue algumas ferramentas de acordo com as profissões às quais elas estão tipicamente associadas. Há, por exemplo, o martelo de um sapateiro, de um pedreiro, de um serralheiro, há o martelo de um serralheiro americano e o alicate inglês e o francês. Até os parafusos estão relacionados com seus países de origem. Sobre isso, basta também observar a diferença entre as polegadas das roscas inglesas Whitworth e as americanas Sellers. Note-se que os traços técnicos pelos quais esses tipos de parafusos diferem são apenas signos utilitários potenciais. Apenas quando são associados com as tecnologias da Europa continental, inglesa ou americana, ou de outros países, eles se tornam signos socioculturais.

\subsubsection{O signo mítico}

O estudo dos mitos conectados com as mercadorias tem sido um tópico favorito na pesquisa semiótica da publicidade. No entanto, a definição de mito nesse contexto tem permanecido bem vaga. Barthes (1964a) e outros discutiram os significados mitológicos sem diferenciá-los das conotações simples e, em particular, dos significados ideológicos. 
Para evitar essas ambigüidades, definiremos o signo mítico no sentido mais próximo de mythos, na Grécia antiga, que significa "uma narrativa poética e legendária”, em oposição a um relato histórico: mito, nesse sentido, é uma narrativa com um nível secundário de significado, em adição ao significado primário. Refere-se, assim, a estórias e fragmentos de estórias com uma dimensão metafórica. Há velhos e novos mitos. Os antigos se desenvolveram dentro das tradições religiosas e literárias da cultura. Os novos estão sendo criados pelos meios de massa, inclusive a publicidade.

Exemplos de novos mitos podiam ser encontrados nas campanhas publicitárias, agora proibidas, como as de cigarros Marlboro ou Camel: cada novo anúncio trazia um episódio subseqüente de uma estória de aventuras aparentemente sem fim. Os episódios dessas seqüências eram apresentados sob a forma de imagens e seu conteúdo narrativo sugestivo permanece por ser escrito. É a narrativa de um herói solitário em uma luta bemsucedida contra as forças da natureza, seja ele um cowboy laçador que prova seu domínio sobre um rebanho de gado selvagem, ou o corajoso aventureiro que alcança margens exóticas em seu barco primitivo. Não obstante o cenário variável do oeste americano ou das regiões exóticas, a mensagem mítica permanece imutável: é o mito da auto-realização sem rédeas, em harmonia com a natureza, como uma contra-imagem da vida real confinada ao mundo industrializado poluído.

Outro mito moderno com uma dimensão histórica, ou melhor, pseudo-histórica foi criado em muitos dos episódios da campanha do cigarro Virginia Slims. O tópico desse mito era a história do progresso na emancipação das mulheres, uma história que, da perspectiva interessada do anunciante, está conectada com a propagação do ato de fumar. Esse falso mito, condensado no slogan "You've come a long way, baby" (Você percorreu um longo caminho, querida) foi muito acertadamente rejeitado por consumidoras críticas que se ressentiram do fato de que o predicado de progresso para o desenvolvimento de fumar tenha resultado simplesmente em baby.

Antigos mitos se referem a histórias conhecidas independentemente de qualquer associação com as mercadorias. Alguns produtos se referem a tais mitos no seu nome de marca, por exemplo, Cognac Napoleão ou Highland Queen Scotch Whisky. Freqüentemente, os anúncios descrevem tais mitos em contigüidade com o produto, tendo por finalidade produzir uma transferência de significado da narrativa imagética para o produto. Por exemplo, o anúncio de uma publicidade para "Highland Queen Scotch" mostra o produto contra o fundo de uma pintura que se refere ao mito nacional da Escócia, a Rainha Mary da Escócia, aclamada por suas tropas em frente do Castelo de Edinburgh, 1561. 


\subsection{Um exemplo}

As quatro molduras semióticas da mercadoria como signo, discutidas acima, podem ser brevemente ilustradas em uma antiga publicidade de carro que uniu essas molduras de modo exemplar. Trata-se do Thunderbird Esporte da Ford. A mensagem buscava criar um signo multi-molduras cujo foco principal estava no signo utilitário com componentes semânticos do tipo "Motor 6.0, litro V-8, $150 \mathrm{hp}$, equipamento padrão" etc. O signo econômico consistia na oferta de três anos de garantia e serviços para a vida toda. $\mathrm{O}$ signo sociocultural encontrava-se no nome da marca associada com esportes (Thunderbird Esporte) e na referência textual a passeios e viagens. O signo mítico estava também relacionado ao nome da marca, visto que Thunderbird é um pássaro mítico que, para os índios americanos, provoca relâmpagos e trovões. Esse signo também aparecia na marca sob a forma de um pássaro de asas estendidas. Além disso, esse mesmo signo ficava implícito no slogan, "Ir como o vento". Esses significados intencionados não eram inerentes à mensagem. Aos consumidores que não tinham familiaridade, ou tinham apenas vago conhecimento do mito indígena, o signo mítico não se atualizava ou permanecia fragmentário. Aqueles que nada sabiam sobre motores e outros detalhes técnicos também não desenvolviam um signo utilitário.

\section{PROCESSOS DE SEMIOTIZAÇÃO DAS MERCADORIAS}

Depois de discutir as molduras semióticas mais típicas, a relação dessas molduras no processo de semiotização das mercadorias deve ser determinada. Essa relação depende do tipo de mercadoria e será discutida mais abaixo, depois da apresentação das categorias prototípicas de produtos.

\subsection{Categorias prototípicas de produtos}

Embora tenha sido mostrado que todas as mercadorias podem ser decodificadas dentro de suas três principais molduras, discutiremos agora que há molduras semióticas prototípicas para muitas categorias de produtos, apesar de que possa haver imprecisão tipológica em alguns casos. Assim, há produtos prototipicamente utilitários e prototipicamente socioculturais. A primeira categoria inclui ferramentas, máquinas e alimentos básicos. O segundo compreende produtos tais como vestimentas excêntricas, 
flores, souvenirs, romances, pinturas ou performances de ópera. A terceira categoria maior de produtos prototipicamente comerciais, compreendendo mercadorias tais como ações, títulos do Estado, moedas estrangeiras e dinheiro em geral, não será discutida em detalhes aqui.

A categoria à qual um produto prototipicamente pertence não é inerente ao produto ele mesmo, mas observável empiricamente a partir do modo de consumo predominante e da primazia histórica ou genética na evolução de uma mercadoria. Para um produto predominantemente utilitário, a dimensão cultural é secundária no uso atual e/ou na história do produto. Assim, liquidificadores são prototipicamente produtos utilitários. O design industrial deles é secundário em relação à sua utilidade. Moedas são prototipicamente produtos comerciais. $\mathrm{O}$ fato de que alguns indivíduos usem moedas na forma de braceletes tem pouco a ver com a evolução e o uso predominante dessa mercadoria. Entretanto, as mercadorias podem mudar sua classe prototípica. Assim, máquinas de escrever, que são colecionadas devido ao seu design industrial fora de circulação, mudaram da categoria de utilitárias para a de socioculturais.

\subsection{Processos prototípicos de semiotização}

O processo típico de semiotização de produtos predominantemente utilitários, discutido acima, é diferente daquele das mercadorias prototipicamente socioculturais.

\subsubsection{Produtos prototipicamente utilitários}

O processo prototípico na gênese dos signos das mercadorias primariamente utilitárias segue a seguinte ordem: signo utilitário (u), signo econômico (e), signo sociocultural (s-c). A maioria das discussões sobre semiotização das mercadorias, via de regra, concentra-se na terceira fase do processo. McCracken (1986: 74), por exemplo, estuda a fase de semiotização na discussão da transferência do significado cultural para os produtos.

A semiotização prototípica desta categoria de produtos é característica da semiose em um mundo econômico de "razão prática". Isso pode ser mais bem ilustrado pelo exemplo de simples ferramentas e instrumentos técnicos. Se vistos de algum modo como signos, martelos e pregos são, antes de tudo, signos utilitários. Como signos comerciais, eles dependem de suas qualidades utilitárias: um consumidor racional avalia seu preço na base de seu valor de uso. O produtor também avalia o significado comercial da mercadoria 
como signo (isto é, custos e lucro) em termos de uma semântica utilitária relacionada com materiais, produção e distribuição no varejo. Os significados socioculturais mais raros associados com ferramentas, tais como pregos e parafusos, resultam de uma adição semântica (uma conotação terciária) aos outros dois níveis. Eles pressupõem o signo utilitário (de cujos traços técnicos eles derivam) e são secundários ao signo comercial.

Outro produto utilitário que é prototipicamente semiotizado na ordem $\mathrm{u} \rightarrow \mathrm{e} \rightarrow \mathrm{s}-\mathrm{c}$ é o leite: seu valor nutricional e gosto são primariamente (u), por exemplo, isso é o que conta para a criança, seu preço (e) é secundário, tanto é que o comércio do leite veio mais tarde na evolução da cultura do que seu consumo, e as conotações socioculturais, tais como "vida do campo" ou "natureza" (s-c), vieram ainda mais tarde e são assim terciárias na evolução deste produto. Mas nem todos os alimentos seguem a ordem dessa semiotização prototípica. Refrigerantes, por exemplo, são mercadorias cuja imagem de marca é criada em um processo de semiotização que é atípico nos produtos alimentícios.

Alguns produtos que devem preencher uma função utilitária no seu uso prático, apesar disso não são semiotizados na ordem de $u \rightarrow e \rightarrow s-c$, mas na ordem $u \rightarrow$ s-c $\rightarrow$ e. Nessa classe de mercadorias, não apenas a utilidade prática (u), como também o estilo ou design industrial (s-c) são fatores essenciais que determinam o valor comercial (e) do produto (por exemplo, um móvel da moda ou uma porcelana ornamentada). Essas mercadorias utilitárias são menos prototípicas. Elas se situam entre a categoria prototipicamente utilitária e a sociocultural.

\subsubsection{Produtos prototipicamente socioculturais}

A ordem prototípica de semiotização dessa categoria de produto é s-c $\rightarrow$ e. Por exemplo, distintivos ou romances são objetos primariamente de cultura e seu valor comercial vem em segundo lugar. Às vezes, há uma terceira fase de semiotização (s-c $\rightarrow \mathrm{e} \rightarrow \mathrm{u}$ ): um livro de capa dura tem uma utilidade prática maior (u) do que uma edição de capa mole. Distintivos de um tipo são mais duráveis do que outros que podem quebrar facilmente. Um signo prático utilitário associado com uma escultura de barro, em contraste com uma de bronze, é que aquela se quebra com mais facilidade. Se o objeto material é predominante até o ponto de afetar essencialmente o seu preço, por exemplo, uma escultura de ouro, a ordem de semantização pode ser s-c $\rightarrow \mathrm{u} \rightarrow \mathrm{e}$.

\subsection{Modos desviantes de semiotização}


São três os modos desviantes de semiotização: o atípico, o falacioso e o degenerado.

\subsubsection{Semiotização atípica do produto}

Esse processo pode ser encontrado na esfera sociocultural. Ele caracteriza objetos cujo status de mercadoria é objetado ou rejeitado pelas sociedades ou culturas. Nesse sentido, um ser humano vendido como um escravo é uma mercadoria atípica nos nossos tempos. Objetos sagrados são igualmente mercadorias atípicas em culturas que acreditam que relíquias e igrejas não deveriam ser vendidas $(\mathrm{s}-\mathrm{c} \rightarrow \mathrm{e})$. Até certo ponto, objetos de arte são mercadorias atípicas também. Distinguindo-se de qualquer outra transação comercial, a venda de um Rembrandt a um país estrangeiro, por exemplo, é vista como um ato nãopatriótico.

Em um caso extremo de semiotização atípica, o objeto de arte pode mesmo se tornar um signo utilitário $(\mathrm{s}-\mathrm{c} \rightarrow \mathrm{u}$ ), quando, por exemplo, ele é considerado de um ponto de vista puramente utilitário, no caso em que um consumidor compra uma pintura pelo motivo primário de pendurá-lo na parede a fim de cobrir manchas de infiltração na parede.

\subsubsection{Falácias semióticas}

Reversões na ordem de semantização nas quais o consumidor toma o signo prototipicamente secundário da mercadoria como base de avaliação do signo primário constituem falácias semióticas. Há muito tempo, Veblen (1899) descreveu um desses tipos de falácias: compra de uma mercadoria de acordo com o princípio "caro, portanto, bom" (e $\rightarrow \mathrm{u})$.

Outra falácia clássica na semiotização de mercadorias foi estudada na conexão com o marketing das marcas cola (Coca, Pepsi). Pressupõe-se que muitos consumidores percebem certas marcas de cola primariamente como signos socioculturais (cf. Coca-Cola como a encarnação do mito americano) e avaliam seu sabor nessa base ( $\mathrm{sc} \rightarrow \mathrm{u}$ ). Embora muitos consumidores possam não ser afetados por essa falácia, outros evidentemente cometem a falácia de preferir uma marca mítica de cola cujo sabor eles não identificariam em um teste cego de sabor.

\subsubsection{Semiotização degenerada}

Este modo de semiotização da mercadoria caracteriza-se pelo conflito ou mesmo 
contradição entre traços semióticos primários e secundários das mercadorias. O produto é consumido devido a características semióticas secundárias positivas, a despeito de consideráveis deficiências de seus traços prototipicamente primários. Por exemplo, o signo sociocultural da mercadoria está em conflito com o signo econômico quando o produto é consumido mesmo no caso de o consumidor não ter posses para isso, por exemplo, um carro de prestígio.

Há conflito entre o signo utilitário e o sócio econômico quando o produto é consumido mesmo não sendo prático, por exemplo, moda de roupas muito justas, ou um alimento a despeito de seu sabor desagradável. Por exemplo, jovens fumando ou bebendo cerveja pela primeira vez, a fim de serem aceitos por seus consumidores pares, consomem um produto como um signo sociocultural que está em contradição com o signo utilitário do sabor, pois este sinaliza, em primeiro lugar, a aversão.

\section{A LINGUAGEM DAS MERCADORIAS COMO UM SISTEMA}

Se as mercadorias merecem ser consideradas linguagem, elas deveriam ser analisáveis em termos de relações paradigmáticas e sintagmáticas, estes dois tipos de relações que formam os dois eixos clássicos da estrutura lingüística. Enquanto o eixo paradigmático se refere às alternativas (lexicais ou semânticas) e oposições a um signo, o sintagmático refere-se à sintaxe, as regras para a combinação dos signos.

\subsection{A dimensão paradigmática}

Barthes (1964a: 63; 1967) esteve entre os primeiros a propor uma análise da dimensão paradigmática das mercadorias. Depois dele, a pesquisa sobre o consumidor americano começou com a exploração dessa dimensão do mercado (cf. Mick 1986: 2023). O estudo da dimensão paradigmática de um sistema semiótico deve explorar tanto as similaridades quanto as diferenças entre os objetos sob consideração. De acordo com a semelhança semântica, as unidades de um sistema são agrupadas para formar classes de signos. A classificação das mercadorias por marcas e tipos de produtos, realizada pelo gerente de um supermercado, reflete uma possível classificação semiótica das mercadorias como signos práticos (utilitários). Pelas diferenças entre signos, as mercadorias entram em oposições que constituem estruturas do sistema semiótico.

$\mathrm{Na}$ linguagem das mercadorias, essas estruturas de oposição são enfatizadas pela concorrência entre marcas e classes de produtos. A tese de Saussure, de que um sistema 
semiótico, e com ele o significado de seus signos só se constitui pelas diferenças entre seus elementos, é particularmente verdadeira para a linguagem das mercadorias. Uma vez que a competição é o motor de um mercado livre, deveria ser evidente que a linguagem das mercadorias é, sem dúvida, um sistema semiótico. Na intenção dos produtores e publicitários, essa linguagem tem até mesmo uma natureza semiótica radical. A linguagem das mercadorias luta por maximizar as diferenças e minimizar as semelhanças entre produtos concorrentes. A mais convincente ilustração dessa tese encontra-se na competição entre as chamadas marcas genéricas e suas réplicas materialmente idênticas, vendidas em embalagens diferentes, sob nomes diferentes e preços mais altos.

\subsection{A sintaxe das mercadorias}

Se as mercadorias são combinadas pelo produtor e pelo consumidor de uma maneira significativa, semelhante à combinação das palavras em uma sentença, essa combinação resultará em uma mensagem da mercadoria. As regras que determinam essas combinações no espaço e tempo formam a dimensão sintagmática da linguagem das mercadorias. Barthes (1964a: 63) propôs estudar essas combinações de partes das roupas em vestimentas, comida em menus ou peças de mobília na organização em uma sala como estruturas sintagmáticas. Kehret-Ward (1987) também propôs estudar as combinações entre produtos como uma sintaxe das mercadorias.

Todavia, os estudos das combinações de produtos levaram apenas à descoberta de sintaxes muito rudimentares de mercadorias. Com exceção de algumas regras culturais ou estéticas que restringem as possibilidades de combinar produtos, tais como toalhas de mesa, comida, peças de mobília, ou suas cores, formas e tamanhos, há pouca evidência de uma sintaxe sistemática das mercadorias. Note-se que a transição de palavras para sentenças em uma língua leva a duas dimensões essencialmente novas na sintaxe, restrições de ordem linear e predicação, isto é, a formação de um novo significado holístico pela combinação de um argumento (isto é, de um assunto) com um predicado. Diferentemente da sintaxe linear da língua, as fracas regras culturais e estéticas da sintaxe dos produtos são essencialmente regras de combinação, que prescrevem ou restringem a ordem dos elementos em uma possível mensagem pluridimensional das mercadorias.

Não parece haver nada comparável ao princípio de predicação na sintaxe das mercadorias. As combinações dos produtos são basicamente aditivas, mesmo quando essa adição resulta em constelações típicas de produtos, tais como "garfo e faca", "xícara e pires", "mesa e cadeira", ou combinações similares de produtos que são, por vezes, 
vendidos apenas como conjuntos. Em tais constelações de produtos, do tipo $\mathrm{A}+\mathrm{B}$, o significado cultural de A não é especificado ou modificado por B do mesmo modo que o predicado "dourado" modifica o argumento "garfo" na predicação "O garfo é dourado". Em contraste com sua dimensão paradigmática altamente estruturada, devemos concluir que a linguagem das mercadorias possui uma sintaxe bastante fraca.

\section{REFERÊNCIAS BIBLIOGRÁFICAS}

APPADURAI, A., The Social Life of Things. Cambridge: Cambridge University Press, 1986.

ARONOF, M. 'Automobile semantics', in V.P. Clark et al. (eds.), Language. New York: St. Martin's Press, 1985 .

BARTHES, R., Elements of Semiology. London: Cape, 1964.

"Rhetoric of the image", in BARTHES, R., Image-Music-Text. New York: Hill and Wang, 1964.

BARTHES, R., The Fashion System. New York: Hill and Wang, 1967.

BAUDRILLARD, J., Le Système des Objets. Paris: Gallimard, 1968.

For a Critique of the Political Economy of the Sign. St. Louis, MO: Telos, 1972.

BELK, R., BAHN, K., MAYER, R., 'Developmental recognition of consumption symbolism', Journal of Consumer Research, 1982.

CARREIRA, J., "Da estratégia do anunciante à comunicação publicitária: o caminho do significado", in HiperPublicidade. Fundamentos e interfaces, PEREZ, C. e BARBOSA, I. São Paulo: Thomson, 2007.

CSIKSZENTMIHALYI, M., ROCHBERG-HALTON, E., The Meaning of Things. Cambridge: Cambridge University Press, 1981.

ISHERWOOD, D., ISHERWOOD, M., ISHERWOOD, B., The World of Goods. New York: Norton, 1979.

ECO, U., A Theory of Semiotics. Bloomington, IN: Indiana University Press, 1976.

HIRSCHMAN, E., HOLBROOK, B., Symbolic Consumer Behavior. Ann Arbor, MI: Association for Consumer Research, 1981.

HOLMAN, R., “Apparel as communication”, in HIRSCHMAN, E., HOLBROOK, M., Symbolic Consumer Behavior. Ann Arbor, MI: Association for Consumer Research, 1981a.

, 'Product use as communication', Review of Marketing, 1981b.

KEHRET-WARD, T., "Combining products in use: How the syntax of product use affects 
marketing decisions", in UMIKER-SEBEOK, J., Marketing and Semiotics. Berlin: Mouton de Gruyter, 1987.

KOCH, W., Philosophic der Philologie und Semiotik. Bochum: Brockmeyer, 1986.

KOPYTOFF, I., "The cultural biography of things: Commodization as process", in APPADURAI, A., The Social Life of Things. Cambridge: Cambridge University Press, 1986.

KRAMPEN, M., Meaning in the Urban Environment. London: Pion, 1979. LANGHOLZ

LEYMORE, V., Hidden Myth. New York: Basic Books, 1975.

LEFEBVRE, H., Le Langage et la Société. Paris: Gallimard, 1966.

LEVY, S., Marketplace Behavior. New York: AMACOM, 1978.

LURIE, A., The Language of Clothes. New York: Random, 1981. MCCRACKEN, G. "Culture and consumption", Journal of Consumer Research, 1986. MICK, D., "Consumer research and semiotics", Journal of Consumer Research, 1986.

MOLES, A., Theorie des Objects. Paris: Ed. Universitaire, 1972.

MUKAŘOVSKÝ, J., Structure, Sign, and Function. New Haven, CT: Yale University Press, 1978.

NÖTH, W., Dynamik semiotischer Systeme. Vom a.e. Zauberspruch zum illustrierten Werbetext. Stuttgart: Metzler, 1977.

_.. Handbuch der Semiotik. Stuttgart: Metzler, 1985.

"Advertising: The frame message", in UMIKER-SEBEOKN J., Marketing and Semiotics. New Directions in the Study of Signs for Sale. Berlin: Mouton de Gruyter, 1987a.

_. "Advertising, poetry, and art: Semiotic reflections on aesthetics and the language of commerce", Kodikas/Code, 1987b.

PEIRCE, C., Collected Papers, ed. C. Hartshorne, P. Weiss and A.W. Burks. Cambridge, MA: Harvard University Press, 1931.

PEREZ, C. Signos da marca. Expressividade e sensorialidade. São Paulo: Thomson, 2004.

POPPER, K., JOHN, C. The Self and its Brain: An Argument for Interactionism. Heidelberg and New York: Springer, 1977.

ROSSI-LANDI, F. Linguistics and Economics. The Hague: Mouton, 1975.

SAHLINS, M. Culture and Practical Reason. Chicago, IL: Chicago University Press, 1976.

SAUSSURE, F., Course in General Linguistics. New York: McGraw-Hill, 1916.

STANLEY, T. Cola preferences: Disguised taste vs. brand evaluations. Advances in Consumer Research, 1978. 
A linguagem das mercadorias

de Lucia Santaella e Winfried Nöth

UMIKER-SEBEOK, J. Marketing and Semiotics. New Directions in the Study of Signs for Sale. Berlin: Mouton de Gruyter, 1987.

VEBLEN, T. The Theory of the Leisure Class. New York: Modern Library, 1899.

WALLENDORF, M., ARNOULD, E. "My favorite things: A cross-cultural inquiry into object attachment, possessiveness and social linkage", Journal of Consumer Research, 1988.

WILLIAMSON, J. Decoding Advertisements. London: Boyars, 1987.

Artigo recebido em 15/3/2009.

Aprovado em 29/4/2009. 